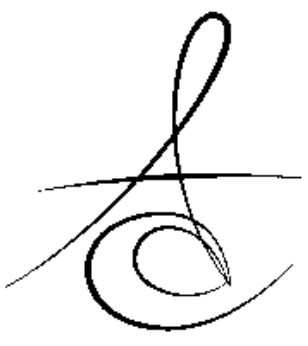

\title{
TERMOMEKANİK YAŞLANDIRMANIN FARKLI SERAMİK ABUTMENTLARA SAHİP İMPLANTLARIN STABİLİTESİNE ETKİSİ ${ }^{\neq}$
}

\section{EFFECT OF THERMOMECHANICAL AGING ON THE STABILITY OF IMPLANTS WITH DIFFERENT CERAMIC ABUTMENTS ${ }^{\neq}$}

\author{
Doç. Dr. Merve BANKoĞLU GÜNGÖR* Prof. Dr. Seçil KARAKOCA NEMLİ* \\ Dt. Meral BAĞKUR* \\ Dr. Öğr. Üyesi. Mustafa KOCACIKLI*
}

Makale Kodu/Article code: 3440

Makale Gönderilme tarihi: 01.04.2017

Kabul Tarihi; 13.03.2018

\section{öz}

Amaç: $\mathrm{Bu}$ çalışmanın amacl, 3 farklı seramik abutment kullanılarak restore edilen dental implantların termomekanik yaşlandırma öncesinde ve sonrasında stabilitelerinin Rezonans Frekans Analizi yöntemi ile değerlendirilmesidir.

Gereç ve Yöntem: Bu çalışmada, Lityum disilikat abutment, Prefabrike zirkonya abutment ve Zirkonya abutment olmak üzere üç çalışma grubu $(n=5)$ oluşturuldu. Lityum disilikat ve zirkonya abutment gruplarında, deney örneklerinin elde edilmesi amacıyla, model üzerinde üst sağ birinci kesici diş boşluğuna yerleştirilen implantın, komşu dişlerin ve kapanış ilişkisinin dijital ölçüsü alındı. Sanal modeller üzerinde abutment ve lityum disilikat kron restorasyonları tasarlandı ve üretildi. Prefabrike zirkonya abutment grubunda ise, firma tarafından üretilen hazır zirkonya abutment üzerine lityum disilikat kron restorasyonları tasarlanarak üretildi. Abutmentimplant bağlantısı sağlanan tüm örnekler, sıcaklığı $5^{\circ} \mathrm{C}-55^{\circ} \mathrm{C}$ olan suda $1000 \mathrm{kez}$ ISI döngüsüne ve 50 N'luk kuvvet ile 200000 mekanik siklusa maruz bırakıldı. Yaşlandırma sonrasında, abutment ve kronlar çıkarıldı. İmplantların üzerine üretici firmaya ait Smartpeg'ler yerleştirildi. İmplant stabilite katsayısı (ISQ) değerleri, yaşlandırma öncesi ve sonrasında dört farklı bölgeden (bukkal, palatal, mezial ve distal) ölçülerek kaydedildi. ISQ değerlerinin karşılaştırılması için iki-faktörlü tekrarlanan ölçümlü varyans analizi kullanıldı. Hesaplama ve yorumlamalarda \% 5 'lik önem düzeyi dikkate alındı.

Bulgular: Varyans analizi sonucunda materyalxtermomekanik yaşlandırma interaksiyonunun istatistiksel olarak önemli olmadığı (P>.05), materyal ve termomekanik yaşlandırma faktörlerinin ise istatistiksel olarak önemli olduğu bulundu $(P<.05)$. ISQ değerleri termomekanik yükleme sonrası önemli derecede azaldı $(P<.05)$. Bonferroni testi sonuçları incelendiğinde; Prefabrike zirkonya abutment grubunun Lityum disilikat abutment grubundan anlamlı derecede yüksek ISQ ortalamasına sahip olduğu görüldü $(P<.05)$.

Sonuç: İmplantların yükleme sonrasında stabilitelerindeki değişimi gösteren ISQ değerlerinin azalması, implant ve kemik ara yüzünün sağlamlığında azalmaya işaret olabilir. Ancak bu çalışmada elde edilen sonuçlar yorumlanırken, implantı çevreleyen akrilik rezin materyalinin canlı kemik dokudan farklı özellikler gösterdiği göz önüne alınmalıdır.

Anahtar Kelimeler: Dental implant, Seramikler, Dental implant-kaide tasarımı

\begin{abstract}
Aim: The purpose of the present study was to evaluate the stability of the dental implants with different ceramic abutments before and after thermomechanical aging by Resonance Frequency Analysis.

Material and Methods: In the present study, three experimental groups $(n=5)$ were generated as: Lithium disilicate abutment, Prefabricated zirconia abutment, and Zirconia abutment. For producing the lithium disilicate abutments and Zirconia abutments, digital impressions were taken from the implants which were inserted on the model into the missing area of the upper right central tooth, adjacent and opposite teeth, and buccal side. Abutments and lithium disilicate crown restorations were designed and milled. In the Prefabricated zirconia abutment group, zirconia abutments which were prefabricated by the manufacturer were used. All specimens which the implant-abutment connection was done were subjected to 1000 thermal cycles at 5-55 centigrade degrees water and 200000 mechanical cycles with $50 \mathrm{~N}$ load. The abutments and crowns were removed after aging. Manufacturer's Smartpegs were inserted onto the implants. Implant stability quotient (ISQ) values were measured from the four different sections (buccal, palatal, mesial, and distal) before and after the thermomechanical aging and recorded. Two-way Analysis of Variance with repeated measures was used to compare the ISQ values. The alpha level was set at $5 \%$.
\end{abstract}

Results: Variance analysis showed that materialx thermomechanical aging interaction was not significant $(P>.05)$; however, the effects of the material and thermomechanical aging factors were found to be significant $(P<.05)$. ISQ values were significantly decreased after the thermomechanical aging $(P<.05)$. According to the Bonferroni results, Prefabricated zirconia abutment group showed significant higher ISQ mean values than Lithium disilicate abutment group $(P<.05)$.

Conclusion: Decrease on the ISQ values after aging may be a sign of the decrease on the durableness of implant-bone interface. However, it must be under consideration to evaluate the results of the present study that acrylic resin has different properties than living bone tissue.

Key Words: Dental implant, Ceramics, Dental ImplantAbutment Design

* Gazi Üniversitesi, Diş Hekimliği Fakültesi, Protetik Diş Tedavisi Anabilim Dalı, Ankara.

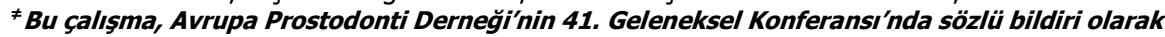

sunuldu (28-30 Eylül 2017, Bükreş, Romanya). 
Atatürk Üniv. Diş Hek. Fak. Derg.

J Dent Fac Atatürk Uni

Cilt:29, Sayı:1, Yıl: 2019, Sayfa, 80-88
BANKOĞLU GÜNGÖR, KARAKOCA NEMLİ, BAĞKUR, KOCACIKLI

\section{GİRİş}

Osseoentegrasyon terimi ilk olarak 1985 ylIında Branemark ve arkadaşları tarafından "sağlıklı kemik doku ve yük taşıyan bir implant yüzeyi arasındaki direkt yapısal ve fonksiyonel birleşim" olarak tanımlanmıştır. ${ }^{1}$ Son yıllarda ise osseoentegrasyon; "implant materyalinin kemik içinde semptomsuz bir şekilde rijit fiksasyonunun sağlanması ve fonksiyonel kuvvetler altında da bu fiksasyonu koruması" yani diğer bir ifade ile "implantın kemik içinde stabil olması" olarak yeniden tanımlanmıştır. ${ }^{2}$ Bu sebeple implantların hem yerleştirildiği andaki stabiliteleri (primer stabilite) hem de iyileşme süresi boyunca olan stabiliteleri (sekonder stabilite) osseoentegre implantların uzun dönem klinik başarısı için önemli bir kriterdir. ${ }^{3}$

Dental implantların stabilitelerinin ölçülmesinde çeşitli klinik ve laboratuvar yöntemler kullanılmaktadır. ${ }^{4-6}$ Bunlardan Meredith ve ark. ${ }^{7,8}$ tarafından ortaya koyulmuş olan rezonans frekans analizi (RFA) dental implantların stabilitesinin belirlenmesinde invaziv olmayan, güvenilir ve objektif bir klinik teknik olarak günümüzde yaygın uygulama alanına sahiptir. Bu yöntemde implant-kemik ara yüzeyinin sağlamlığı, implant-kemik ara yüzeyinde oluşturulan titreşim aracılığı ile ölçülür ve ölçüm sonucu "implant stabilite katsayısı (ISQ)" olarak kaydedilir. ISQ değeri 0-100 arasında değişmektedir, 40 değerin altındaki ölçümler implant stabilitesinin yetersiz olduğunu belirtmektedir. Bir implantın tekrarlanan ölçümlerinde ISQ değerindeki azalma kemik-implant ara yüzünün veya implantı çevreleyen kemiğin sağlamlığında bir

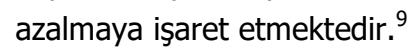

RFA ölçümleri; implantın yerleştirildiği cerrahi aşamada, iyileşme süresi sonunda protetik aşama öncesinde ve klinik fonksiyonu esnasında periyodik olarak yapılabilmektedir. İmplantın yerleştirildiği seansta yapılan ölçüm ile primer implant stabilitesi tespit edilmektedir. Primer implant stabilitesi bir implant için en uygun iyileşme süresinin belirlenmesinde yararlı olabilmektedir. ${ }^{8}$ Ayrıca implantın yerleştirildiği anda elde edilen ISQ değerlerinin bir dental implantın yükleme zamanı için bir kriter olarak kullanılabileceği ve immediyat yüklenen implantların başarısının bir göstergesi olarak kabul edilmektedir. ${ }^{8-10}$ İyileşmesi süresi sonunda protetik aşamaya başlamadan önce yapılan stabilite ölçümleri ile implantların yeterli osseoentegrasyon gösterip göstermediği kontrol edilebilir ve daha uzun bir iyileşme süresi gerektiren implantlar tespit edilebilir. Protetik üst yapının hazırlanmasından sonra klinik fonksiyon altındaki implantların periyodik olarak stabilitelerinin ölçülmesi ise implantın uzun dönem başarısının gözlemlenmesinde kullanılan objektif bir kriterdir. RFA yöntemi ile ileride kaybedilme riski olan implantların erken teşhis edilebileceği ve gerekli önlemlerin alınabileceği bildirilmiştir. ${ }^{7,10}$ Ayrıca farklı geometriye ve yüzey özelliklerine sahip implantların klinik performanslarının karşılaştırılmasında implant stabilitesinin sayısal değerlerinin kullanılması güvenilir bir yöntem olarak kabul edilmektedir. ${ }^{8}$ Ancak bu yöntemin dezavantajı ölçüm yapılması için protetik üst yapının sökülmesi gerekliliğidir. ${ }^{11}$

RFA yöntemi mevcut literatürde genellikle dental implantların başarılarının değerlendirildiği klinik takip çalışmalarında kullanılmıştır. ${ }^{1,8,12-14} \mathrm{Bu}$ yöntem, in-vitro çalışmalarda ise genellikle belirli bir implant tasarımının, farklı kemik kalitesi ve kalınlığının "primer stabilite" üzerine etkisinin incelenmesi amacıyla kullanılmıştır. ${ }^{15-18}$ Fonksiyonel oklüzal yüklerin ve protetik üst yapının implant stabilitesi üzerine etkisi üzerine bilgiye rastlanmamıştır.

Estetik bölgelerde titanyum implant ve abutmentlar, koyu renk bir görüntüye sebep olabilirler. Bu sebeple seramik abutmentların kullanımı gündeme gelmiş ve başta zirkonya abutmentlar olmak üzere seramik abutmentlar son zamanlarda yaygınlaşmıştır. ${ }^{19}$ Zirkonya abutmentlar üretici firmalar tarafından standart olarak üretilmekte veya kişisel olarak hazırlanmaktadır. ${ }^{19,20}$ Prefabrike abutmentlar, ucuz ve kullanım kolaylığına sahip olmalarına rağmen preparasyon gerektirmeleri, çıkış profillerinin kişisel olarak düzenlenememesi ve implant ile birleşim yerinde mekanik komplikasyonların sık görülmesi dezavantajlarına sahiptir. Titanyum bir kaide aracılığıyla implanta vidalanan iki parçalı kişisel seramik abutmentlar ise hem estetik hem de mekanik açıdan bir çok avantaj sağlayan güncel bir uygulamadır. ${ }^{21}$ Zirkonyadan veya lityum disilikattan yapılan bu abutmentlar, Bilgisayar destekli tasarım/Bilgisayar destekli üretim (CAD/CAM) teknolojisi kullanılarak muayenehane ortamında hazırlanabilmektedir. Ancak iki parçalı kişisel seramik abutmentların mekanik özellikleri ve implant ile çevre dokuları üzerindeki biyomekanik etkileri üzerine sınırlı bilgi bulunmaktadır. ${ }^{22-24}$ 
Atatürk Üniv. Diş Hek. Fak. Derg.

J Dent Fac Atatürk Uni

Cilt:29, Sayı:1, Yıl: 2019, Sayfa, 80-88
BANKOĞLU GÜNGÖR, KARAKOCA NEMLİ, BAĞKUR, KOCACIKLI
$\mathrm{Bu}$ in-vitro çalışmanın amacı, 3 farklı seramik abutment kullanılarak restore edilen dental implantların termomekanik yaşlandırma öncesinde ve sonrasında stabilitelerinin RFA yöntemi ile değerlendirilmesidir. Çalışmanın hipotezi farklı abutmentlar ile restore edilen implantların stabilitelerinin yaşlandırma sonrası değişiklik göstermeyeceğidir.

\section{GEREÇ VE YÖNTEM}

Çalışma modellerinin oluşturulması amacıyla, alt-üst çene modellerinden (Frasaco $\mathrm{GmbH}$, Tettnang, Almanya) orta kıvamlı polivinil siloksan ölçü materyali (Variotime, Hereaus Kulzer, Hannau, Almanya) ve standart ölçü kaşıkları ile ölçü alındı. Çalışmada kullanılan implantlar, $4.3 \mathrm{~mm}$ çapında ve $11.5 \mathrm{~mm}$ (NobelReplace, Nobel Biocare, Gothenburg, İsveç) uzunluğundadır. İmplantın üzerine Ti-Base yerleştirilerek, üzerine üst sağ santral dişin modelasyonu yapıldı. Daha sonra modelasyon, alınan ölçü içerisindeki üst sağ santral diş boşluğuna yerleştirildi. İmplant açısının, santral dişin kök açısına uygun olmasına dikkat edildi.

Ölçülere Tip IV day alçıSı üreticinin önerdiği su/toz oranında hazırlanarak döküldü. Böylelikle, üst sağ santral kesici diş çıkarılarak diş boşluğuna implant yerleştirilmiş üst çene modeli ve kapanış için kullanılacak olan alt çene modeli elde edildi. Modeller yarı ayarlanabilir artikülatöre (Stratos 100, Ivoclar Vivadent, Schaan, Lihtenştayn) alındı ve modelasyon model üzerinden uzaklaştırıldı.

Üç adet çalışma grubu aşağıda belirtildiği şekilde oluşturuldu (Resim 1).

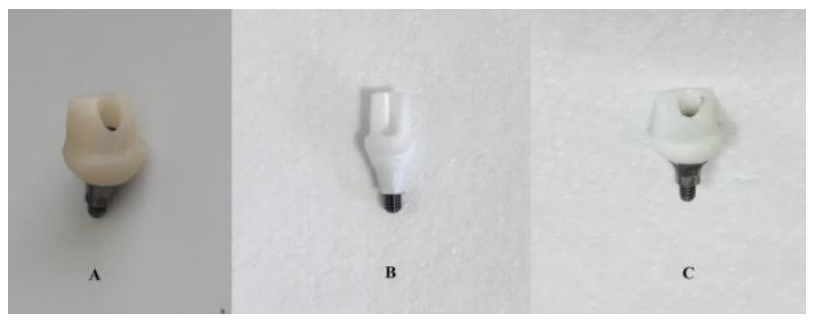

Resim 1. Çalışmada kullanılan üç farklı seramik abutment A) Lityum disilikat abutment B) Prefabrike zirkonya abutment C) Zirkonya abutment

Grup 1: Lityum disilikat (Lds) abutment $(n=5)$,

Grup 2: Prefabrike Zirkonya (PreZr) abutment $(n=5)$,

Grup 3: Zirkonya (Zr) abutment $(n=5)$.

Çalışmada, Grup 1 ve Grup 3 için iki farklı materyalden üretilen (lityum disilikat ve zirkonya) aynı geometrik formda kişisel abutmentlar kullanıldı. Grup 1 ve Grup 3'te yer alan abutmentların üretilmesi amacıyla, çalışma modelinde implant üzerine CEREC sistem ile uyumlu olarak üretilmiş hasta ağzından direkt optik ölçü alınmasını sağlayan Scanpost (tarama başlığı) takıldı. CEREC Omnicam cihazı (Cerec Omnicam, Sirona Dental Systems, Bensheim, Almanya) ile implantın, komşu ve karşıt dişlerin ve kapanış ilişkisinin dijital ölçüsü alındı. Sistemin yazılımı (Cerec SW 4, Sirona Dental Systems, Bensheim, Almanya) tarafından sanal modeller oluşturuldu (Resim 2). CEREC sistemin yazılımı (inLab SW 4.2, Sirona Dental Systems, Bensheim, Almanya), kullanılarak abutmentlar tasarlandı. Grup 1 için abutment, lityum disilikat (IPS e.max CAD abutment, Ivoclar Vivadent, Schaan, Lihtenştayn) bloklardan üretildi. Milleme cihazından çıkan lityum disilikat abutmentlar üretici firmanın talimatları doğrultusunda porselen fırınında (Programat P300; Ivoclar Vivadent, Schaan, Lihtenştayn) kristalize edildi. Grup 3 için abutmentlar, zirkonya bloklardan (inCoris ZI meso blocks, Sirona Dental Systems, Bensheim, Almanya) Grup 1'de anlatıldığı şekilde üretildi. Milleme cihazından çıkan zirkonya abutmentların sinterizasyonu, üretici firmanın talimatları doğrultusunda sinterizasyon fırınında (InFire HTC, Sirona Dental Systems, Bensheim, Almanya) yapıldı. Grup 2 için, üretici firma tarafından sağlanan ve sadece zirkonyadan oluşan zirkonya abutment kullanıldı.

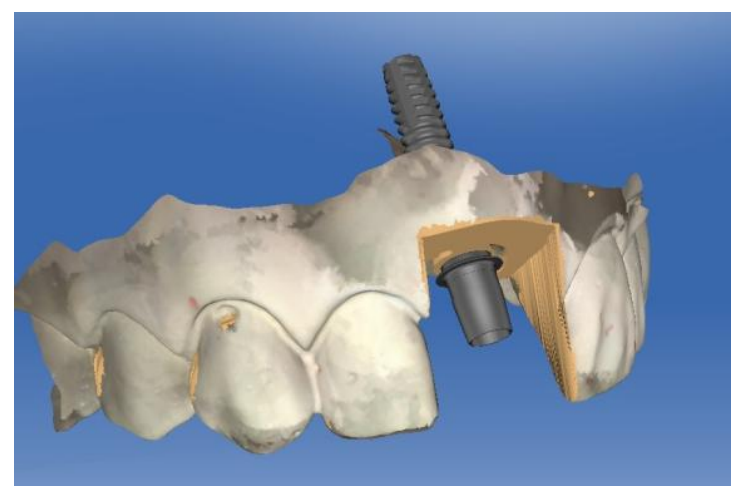

Resim 2. İmplantın sanal model üzerindeki görünümü

Üç grup için de, abutmentların üzerine CEREC sisteminde lityum disilikat kronlar yapıldı. Lityum disilikat üst yapı restorasyonları, yarı kristalize halde bulunan bloklardan (IPS e.max CAD, Ivoclar Vivadent,

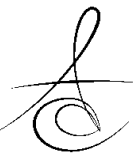


Atatürk Üniv. Diş Hek. Fak. Derg.

] Dent Fac Atatürk Uni

Cilt:29, Sayı:1, Yıl: 2019, Sayfa, 80-88
BANKOĞLU GÜNGÖR, KARAKOCA NEMLİ BAĞKUR, KOCACIKLI
Schaan, Lihtenştayn) üretildi ve üretici firmanın talimatları doğrultusunda porselen fırınında (Programat P300; Ivoclar Vivadent, Schaan, Lihtenştayn) kristalize edildi.

Titanyum base ve seramik abutmentın birleştirilmesi tüm gruplarda aynı şekilde yapıldı. Simantasyon işlemi öncesinde bütün gruplara ait TiBase'ler implant analoglarına bağlandı. Abutment vida deliği ve abutment-analog birleşim bölgesi elastomerik ölçü maddesiyle kapatıldı. Üretici firmanın talimatları doğrultusunda bütün TiBase'ler 50 mikronluk aluminyum oksit partikülleriyle kumlandı. 10 $\mathrm{dk}$. boyunca distile su içerisinde, ultrasonik temizleyicide ve sonrasında buharlı temizleyicide temizlendi. Simantasyon öncesinde kontaminasyon engellendi.

Seramik abutmenta rezin bağlantısını sağlamak amacıyla seramik türüne göre uygun yüzey işlemi uygulandı. Lityum disilikat restorasyonların iç yüzeyi ve lityum disilikat abutmentlar (Grup 1), \% 5'lik hidroflorik asit jeli (IPS Ceramic Etching Gel, Ivoclar Vivadent, Schaan, Liechtenstein) ile 20 saniye boyunca pürüzlendirildi, daha sonra su ile durulanıp, hava ile kurutuldu. Restorasyonların iç yüzeyine ve lityum disilikat abutmentların (Grup 1) yüzeyine 60 saniye silan (Monobond Plus, Ivoclar Vivadent, Schaan, Lihtenştayn) uygulandı ve kurutuldu. Bu yüzey işlemini takiben seramik-metal bağlantısı için üretilmiş rezin siman (Multilink Hybrid Abutment, Ivoclar Vivadent, Schaan, Lihtenştayn) ile kumlanmış TiBase ve abutment birbirlerine simante edildi. Grup 3'te TiBase ile bağlantının sağlanacağı zirkonya yüzeyi 50 mikron büyüklüğünde alüminyum oksit partikülleri ile 2 bar basınç altında kumlanarak pürüzlendirildikten sonra temizlendi. Bu yüzey işlemini takiben seramik-metal bağlantısı için üretilmiş rezin siman (Multilink Hybrid Abutment, Ivoclar Vivadent, Schaan, Lihtenştayn) ile kumlanmış TiBase ve abutment birbirilerine simante edildi. Abutment ve TiBase bağlantısının sağlanmasından sonra, analoglar çıkarıldı.

Lityum disilikat üst yapıları abutmentların üzerine simante etmek için rezin siman (Multilink Automix, Ivoclar Vivadent, Schaan, Lihtenştayn) kullanıldı. Bu simanın seçiminde tam seramik restorasyonlarda kullanıma uygun, dual polimerize bir rezin siman olması göz önünde bulunduruldu. Lityum disilikat restorasyonların simantasyonu öncesinde implantabutment bağlantısı sağlanarak, implantların çene kemiği içindeki durumunu taklit etmek amacıyla implantlar, akrilik bloklara tümü aynı seviyede dikey eksenle 30 derece açı yapacak olacak şekilde gömüldü. Abutmentlar implantlardan ayrılarak; implantların üzerine firmaya ait Smartpeg'ler yerleştirildi. Sonrasında, implantlara ait ISQ değerleri, Ostell Cihazı (Osstell Mentor; Osstell AB, Gothenburg, İsveç) yardımıyla mezial, distal, bukkal ve palatal olmak üzere dört farklı bölgeden ölçülerek kaydedildi ve ortalamaları alındı (Resim 3). ISQ değerlerinin ölçümü tamamlandıktan sonra abutmentlar implantların üzerinde torklandı. Lityum disilikat restorasyonların yüzeyi daha önce anlatıldığı şekilde hazırlandı ve restorasyonlar abutmentların üzerine simante edildi. Lityum disilikat restorasyonların, simantasyon işleminden önce vida delikleri kompozit rezin ile kapatıldı.

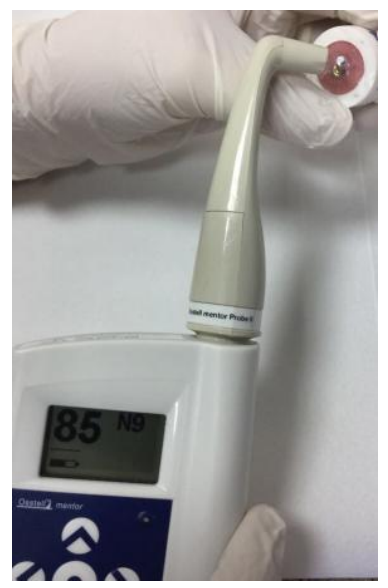

Resim 3. ISQ değerlerinin Osstell ile ölçümü

Her gruba ait örnekler, sıcaklığı 5-55 santigrat derece arasında değişen suda 1000 kez ISı döngüsüne ve 200000 kez mekanik siklusa maruz bırakıldı. Çiğneme kuvvetleri altında restorasyonun maruz kalacağı yüklenmeyi taklit etmek amacıyla örnekler, çiğneme simülatörü cihazına yerleştirildi (Esetron Smart Robotechnologies, Ankara, Turkey) ve beraberinde dikey eksen doğrultusunda $50 \mathrm{~N}$ kuvvet uygulandı. Yaşlandırma, ısı döngüsünün ve mekanik yüklemenin aynı anda uygulanması ile yapıldı. Yaşlandırma yapıldıktan sonra restorasyonlar ve abutmentlar implantların üzerinden uzaklaştırılarak ISQ değerlerinin ölçümü tekrarlandı. 


\section{Istatistik Analiz}

Varyans analizinin normallik ve varyansların homojenliği varsayımları sırasıyla Kolmogorov-Smirnov testi ve Levene testi ile kontrol edildi. Grupların termomekanik yaşlandırma öncesi ve sonrası ISQ değerlerinin karşışaştırıması için iki-faktörlü faktörlerden birinin seviyeleri tekrarlanan ölçümlü varyans analizi kullanıldı. Farklı ortalamaların belirlenmesinde Bonferroni çoklu karşılaştırma testi kullanııld. Bonferroni testi sonuçları tanıtıcı istatistik değerlerinin yanında harfli gösterim şeklinde ifade edildi. Hesaplama ve yorumlamalarda \% $5^{\prime}$ lik önem düzeyi dikkate alındı. Tüm hesaplamalar IBM SPSS statistics for Windows, version 24 (IBM Corp., Armonk, N.Y., ABD) istatistik paket programı ile yapıldı.

\section{BULGULAR}

ISQ değerleri için ortalama ve standart sapmaları içeren tanımlayıcı istatistikler Tablo $1^{\prime}$ de verildi. Yapilan varyans analizi sonucunda materyalxtermomekanik yaşlandırma interaksiyonunun istatistiksel olarak önemli olmadığı görülmektedir (P>.05). Materyal ve termomekanik yaşlandırma faktörlerinin esas etkileri ise istatistiksel olarak önemli bulundu (sırasıyla, $P<.01 ; \mathrm{P}<.05$ ). Materyallere ait yaşlandırma öncesi değerler incelendiğinde; en yüksek ISQ değeri Prefabrike zirkonya abutment grubunda $80.65 \pm 1.80$ olarak bulundu, onu sirasiyla lityum disilikat abutment (79.75 \pm 0.78$)$ ve zirkonya abutment (78.70 \pm 2.24$)$ grupları izledi. Varyans analizi sonuçlarına göre ISQ değeri termomekanik yaşlandırma sonrası önemli derecede azaldı $(P<.05)$. Farklı grupların belirlenmesi amacıyla yapılan Bonferroni testi sonuçları harfli gösterim şekilde ortalamaların yanında verildi. Bonferroni testi sonuçları incelendiğinde; Prefabrike zirkonya abutment grubunun Lityum disilikat abutment grubundan istatistiksel olarak önemli derecede yüksek ISQ ortalamasına sahip olduğu görülmektedir $(P<.05)$. Zirkonya grubunun ISQ ortalaması ise hem Lityum disilikat hem de Prefabrike zirkonya abutment ortalamasından farklı bulunmadı (P>.05).

Tablo 1. ISQ değerleri için ortalama ve standart hataları içeren tanımlayıcı istatistikler

\begin{tabular}{c|c|c|c|c}
\hline Materyal & $\mathrm{n}$ & $\begin{array}{c}\text { Termomekanik } \\
\text { yaşlandırma } \\
\text { öncesi } \\
\text { ISQ değerleri }\end{array}$ & $\begin{array}{c}\text { Termomekanik } \\
\text { yaşlandırma } \\
\text { sonrası ISQ } \\
\text { değerleri }\end{array}$ & $\begin{array}{c}\text { Toplam } \\
(\mathrm{n}=10)\end{array}$ \\
\cline { 2 - 5 } & Ortalama $( \pm \mathrm{SH})$ & Ortalama $( \pm \mathrm{SH})$ & $\begin{array}{c}\text { Ortalama } \\
( \pm \mathrm{SH})\end{array}$ \\
\hline $\begin{array}{c}\text { Lityum } \\
\text { disilikat }\end{array}$ & 5 & $79.75 \pm 0.78$ & $67.90 \pm 0.78$ & $\begin{array}{c}73.83 \pm 2.04 \\
\mathbf{B}\end{array}$ \\
\hline $\begin{array}{c}\text { Prefabrike } \\
\text { zirkonya }\end{array}$ & 5 & $80.65 \pm 1.80$ & $79.15 \pm 2.55$ & $\begin{array}{c}79.90 \pm 1.50 \\
\mathbf{A}\end{array}$ \\
\hline Zirkonya & 5 & $78.70 \pm 2.24$ & $73.88 \pm 3.60$ & $\begin{array}{c}76.29 \pm 2.15 \\
\mathbf{A B}\end{array}$ \\
\hline Toplam & 15 & $79.70 \pm 0.95$ a & $73.64 \pm 1.85 \mathbf{b}$ & \\
\hline P değeri & \multicolumn{2}{|l}{ Materyal=0.009* } \\
& $\begin{array}{c}\text { Temomekanik yaşlandırma }=0.029 * * \\
\text { MateryalxTermomekanik yaşlandırma }=0.131^{* * *}\end{array}$ \\
\hline
\end{tabular}

SH: Ortalamanın standart hatası

*Materyal faktörü, ISQ değerleri üzerinde etkilidir $(P=.009$, $P<.05)$.

**Termomekanik yaşlandırma faktörü, ISQ değerleri üzerinde etkilidir $(P=.029, P<.05)$.

***Materyal ve termomekanik yaşlandırma faktörü arasındaki interaksiyon istatistiksel olarak önemli değildir $(P=.131$, P>.05).

Dikey olarak, materyallere ait toplam ISQ değerlerinde ortak büyük harfe sahip gruplar arasındaki değerler istatistiksel olarak anlamlı farklılığa sahip değildir $(P>.05)$.

Yatay olarak, termomekanik yaşlandırma öncesi ve sonrası toplam ISQ değerleri birbirinden istatistiksel olarak anlamlı farklılık göstermektedir $(P<.05)$.

\section{TARTIŞMA}

Çalışmada elde edilen ISQ değerlerinin termomekanik yaşlandırma sonrasında anlamlı bir azalma göstermesi sebebiyle çalışmanın hipotezi geçersiz oldu. İmplantların yükleme sonrasında stabilitelerindeki azalmayı gösteren ISQ değerlerinin azalması implant ve kemik ara yüzünün sağlamlığında azalmaya işaret olabilir. Sürekli oklüzal yüklerin, özellikle fizyolojik sınırların üzerinde olanların, implantı çevreleyen kemik dokuda mikro gerilimlere yol açabileceği bildirilmiştir. ${ }^{25}$ Ancak bu çalışmada elde edilen sonuçlar yorumlanırken, implantı çevreleyen akrilik rezin materyalinin canlı kemik dokudan farklı özellikler gösterdiği göz önüne alınmalıdır. Canlı kemik dokunun yoğunluğu sabit değildir, aynı anda sürekli olarak gerçekleşen yapım ve yıkım ile değişir ve değişimler implant çevresindeki kemiğin özelliklerinin de değişiklik göstermesine sebep olur. ${ }^{26,27}$ Bununla beraber Wolff kanunu'na göre implantlara gelen 
Atatürk Üniv. Diş Hek. Fak. Derg.

J Dent Fac Atatürk Uni

Cilt:29, Sayı:1, Yıl: 2019, Sayfa, 80-88
BANKOĞLU GÜNGÖR, KARAKOCA NEMLİ, BAĞKUR, KOCACIKLI fonksiyonel yüklerin implant çevresi kemikte meydana getirdiği stresler yeni kemik oluşumunu stimüle ederken ve yeterli düzeyde strese maruz kalmayan kemikte rezorbsiyon meydana gelir. ${ }^{28}$ Buna göre canlı kemik dokuya yerleştirilen ve sürekli fonksiyonel oklüzal kuvvetlere maruz kalan dental implantların stabilitelerinin zamanla artması beklenir. Fonksiyon altında implant stabilitesinin arttığını gösteren klinik çalışmalar da bulunmaktadır. ${ }^{29-32}$ İmplantı çevreleyen kemik dokunun canlı olmayan yapay bir materyal ile taklit edildiği bu çalışmanın sonucunda, fonksiyonel yüklere maruz kalan implantların stabilitelerinin azaldığı gözlemlendi. Bu bulgu, kanlanmasını ve canlılı̆ını yitirmiş kemik dokuda oklüzal kuvvetlerin implant stabilitesini azaltabileceğine işaret olabilir.

Dental restorasyonların uzun dönemli kullanım esnasında performanslarının değerlendirilmesi için, içinde bulundukları ağız ortamının taklit edilerek test edildiği koşullar sağlanmalıdır. Ağız ortamında tekrarlayan yükleme, ısıl değişimler, nem ve pH gibi koşullar söz konusudur. ${ }^{33}$ Klinik olarak dental restorasyonların mekanik başarısızlıkları genellikle aşırı yükleme yerine yıllarca kullanım sonunda yorgunluk kırıkları şeklinde ortaya çıktığı için ağız ortamının taklit edildiği test düzenekleri gerçekçi bilgi vermektedir. Bu çalışmada test örneklerine çiğneme esnasında restorasyonların maruz kaldığı kuvvetleri taklit eden mekanik yükleme ve ısısal değişimleri taklit eden ısısal döngü uygulandı. Ağız ortamında çiğneme esnasında uygulanan tekrarlayan yüklerin bireyler arasında farklılık göstermekle beraber ağzın ön bölgelerinde ortalama $12 \mathrm{~N}-70 \mathrm{~N}$ arasında değiştiği bildirilmiştir. ${ }^{34}$ Ön bölgedeki restorasyonların test edildiği çalışmamızda, bu bölgede dişlerin maruz kaldığı yüksek yükler ve mevcut çalışmalar göz önüne alınarak, $50 \mathrm{~N}$ yük ile yükleme yapıldı. Rosentritt ve ark. ${ }^{35}$ böyle düşük fizyolojik yüklerin deney örneklerinde kırık oluşturamayabileceğini ancak uzun süre boyunca sürekli uygulandıklarında implant veya abutment materyalinde ve bu iki parçayı bağlayan bileşenlerde yorgunluk meydana getirerek başarısızlığa yol açabileceğini bildirmişlerdir. Ancak bu yüklerin implanta iletimi ve implant stabilitesine etkisi bilinmemektedir.

RFA yöntemi mevcut literatürde genellikle klinik çalışmalarda kullanılmıştır. Çekim sonrası immediyat implant yerleştirilmesi ve implantların immediyat yüklenmesinde primer stabilitenin yeterli olması bir kriter olarak kabul edilmiştir. ${ }^{8,10,32,36}$ Klinik çalışmalarda kemiğin kalitesinin, greft materyallerinin, implant tasarımlarının, cerrahi tekniklerin implant stabilitesine etkisi değerlendirilmiştir. 3,5,12,29,30 Ayrıca dental implantların klinik takiplerinde implant başarısının göstergelerinden biri olarak kabul edilmektedir. ${ }^{1,11,29,31}$ RFA yöntemi in-vitro çalışmalarda daha sınırlı olarak kullanılmıştır. Bu çalışmalarda implantlar; hayvan kemikleri, yapay kemik modelleri, poliüretan ve akrilik rezin bloklar içine yerleştirilerek kemik içi durumları taklit edilmiştir. ${ }^{37-40}$ İmplant stabilitesinin değerlendirildiği in-vitro çalışmalarda kortikal kemik kalınlığı, implantın çapı, uzunluğu ve tasarımı, yerleştirme torku, peri-implant kemik kaybı, cerrahi prosedürün stabilite üzerindeki etkisi incelenmiştir. ${ }^{37,39,41,42}$ Ancak protetik üst yapının implant stabilitesi üzerine çalışmaya rastlanmamıştır.

İmplant gövdesini protetik üst yapı ile bağlayan "abutment" adı verilen bileşenin özellikleri, fonksiyonel oklüzal yüklerin implanta ve onu çevreleyen kemiğe iletilmesinde önemli rol oynar. ${ }^{43}$ Abutmentların implant gövdesi ile birleşimi şekli ve yapıldığı materyal, implant bileşenleri ve çevre dokularda ortaya çıkan stresleri etkilemektedir. ${ }^{43,44}$ İmplant-abutment birleşim şekillerinin, bu bağlantının mekanik özellikleri ve biyolojik ortama etkisini değerlendiren çalışmalar, internal bağlantının eksternal bağlantıdan daha stabil olduğunu göstermiştir. ${ }^{43,45}$ Bizim çalışmamızda da implant ile internal bağlantı gösteren abutmentlar kullanıldı.

Seramik abutmentlar yapılarına göre, tamamı seramik abutmentlar (tek parça) ve implant-abutment ara yüzünde ilave metalik yapı içeren abutmentlar (iki parça) olarak 2 ' ye ayrılırlar. ${ }^{46}$ Sailer ve ark. ${ }^{47}$, yaptıkları in-vitro çalışma sonucunda implant-abutment bağlantısının, zirkonya abutmentların teknik sonuçları üzerinde önemli etkileri olduğunu bildirmişlerdir. İki parçalı seramik abutmentlarda implant ve abutment arasındaki internal bağlantının teması metal parça veya titanyum kaide ile sağlanmıştır. ${ }^{48} \mathrm{Bu}$ titanyum kaide seramik abutmentın en zayıf noktası olan seramik-titanyum sürtünmesel temasını ortadan kaldırarak mekanik avantaj sağlamaktadır. Aynı zamanda internal bağlantının stres dağılımında sağladığı avantajlardan da faydalanılır. ${ }^{45}$ Truninger ve ark. ${ }^{49}$ CAD/CAM yöntemi ile hazırlanan ve internal bağlantılı titanyum ara parça ile implanta bağlanan iki parçalı zirkonya abutmentların eksternal bağlantılı olanlara göre daha yüksek yükleme direncine sahip olduklarını

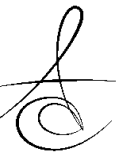


Atatürk Üniv. Diş Hek. Fak. Derg.

J Dent Fac Atatürk Uni

Cilt:29, Sayı:1, Yıl: 2019, Sayfa, 80-88
BANKOĞLU GÜNGÖR, KARAKOCA NEMLİ, BAĞKUR, KOCACIKLI bildirmişlerdir. ${ }^{49}$ Yapılan çalışmalar farklı seramik abutmentların mekanik özellikleri ve teknik komplikasyonları üzerinde yoğunlaşmıştır. ${ }^{46-49}$ Abutmentların implantların kemik içindeki stabilitelerine etkisi üzerine çalışmaya rastlanmamıştır.

\section{SONUÇ}

Çalışmamızda implant ile birleşimi titanyum kaide aracılıyla gerçekleşen 2 farklı seramik abutment ve tamamen zirkonyadan yapılmış prefabrike abutment kullanıldığında termomekanik yaşlandırma sonrası implant stabilitesindeki değişim değerlendirildi. İmplant stabilitesindeki en önemli azalmanın titanyum kaideli Lityum disilikat ve Zirkonya abutmentlarda görüldüğü, prefabrike zirkonya abutmentlara sahip implantların stabilitelerinde ise değişimin çok az olduğu gözlendi. Bunun abutment-implant ile birleşim bölgesinde farklı materyallerin dinamik yükleme esnasında stres dağıımı üzerindeki etkilerinden kaynaklanabileceği düşünülmektedir.

$\mathrm{Bu}$ çalışmadan elde edilen bulgular değerlendirilirken çalışmanın sınırlamaları göz önünde bulundurulmalıdır. Sınırlamalar arasında in-vitro bir çalışma olması başta gelmektedir. Canlı kemik dokunun sürekli devam eden yapım-yıkım döngüsü implant stabilitesini belirleyen çok önemli bir faktör olmasına rağmen in-vitro çalışmalarda canlı dokuların bu fizyolojik süreci ve sürecin kemik-implant ara yüzüne etkisi taklit edilememektedir. Ancak in-vivo çalışmalar materyallerin özellikleri, kullanımları, fonksiyonları ve performansları hakkında standart koşullarda elde edilmiş veri sağlar. Çalışmamızda test örneklerine yaklaşık 1 yıllık klinik kullanımı taklit eden 200000 çiğneme siklusu uygulandı. Dental implantların değerlendirilmesinde en az 5 yıllık fonksiyonu taklit eden çalışmalara ihtiyaç vardır.

Merve Bankoğlu Güngör:ORCID ID:0000-0002-4002-6390 Seçil Karakoca Nemli:ORCID ID:0000-0003-4918-5504 Meral Bağkur:ORCID ID:0000-0001-6487-3984 Mustafa Kocacıklı:ORCID ID:0000-0003-2790-3982

\section{KAYNAKLAR}

1. Brånemark PI, Hansson $\mathrm{BO}$, Adell $\mathrm{R}$, Breine $U$, Lindström J, Hallén $O$, Ohman A. Osseointegrated implants in the treatment of the edentulous jaw.
Experience from a 10-year period. Scand J Plast Reconstr Surg Suppl 1977;16:1-132.

2. Albrektsson TO, Johansson CB, Sennerby $L$. Biological aspects of implant dentistry: osseointegration. Periodontol 2000 1994;2:58-73.

3. Mellado-Valero A, Ferrer-García JC, Calvo-Catalá J, Labaig- Rueda C. Implant treatment in patients with osteoporosis. Med Oral Patol Oral Cir Bucal 2010;15:e52-7.

4. Lachmann $S$, Laval JY, Jäger B, Axmann D, GomezRoman G, Groten M, Weber H. Resonance frequency analysis and damping capacity assessment. Part 2: peri-implant bone loss followup. An in vitro study with the Periotest and Osstell instruments. Clin Oral Implants Res 2006;17:80-4.

5. Tözüm TF, Türkyilmaz I, Yamalik N, Tümer C, Kilinç A, Kilinç K, Karabulut E, Eratalay K. Analysis of the possible impact of inflammation severity and early and delayed loading on nitric oxide metabolism around dental implants. Int J Oral Maxillofac Implants 2005;20:547-56.

6. Türkyilmaz I, Tözüm TF, Tumer C, Ozbek EN. Assessment of correlation between computerized tomography values of the bone, and maximum torque and resonance frequency values at dental implant placement. J Oral Rehabil 2006;33:881-8.

7. Meredith N, Alleyne D, Cawley P. Quantitative determination of the stability of the implant-tissue interface using resonance frequency analysis. Clin Oral Implants Res 1996;7:261-7.

8. Meredith N. Assessment of implant stability as a prognostic determinant. Int J Prosthodont 1998;11:491-501.

9. Meredith N. A review of nondestructive test methods and their application to measure the stability and osseointegration of bone anchored endosseous implants. Crit Rev Biomed Eng 1998;26:275-91.

10. Bischof M, Nedir R, Szmukler-Moncler S, Bernard JP, Samson J. Implant stability measurement of delayed and immediately loaded implants during healing. Clin Oral Implants Res 2004;15:529-39.

11. Sennerby L, Meredith N. Implant stability measurements using resonance frequency analysis: biological and biomechanical aspects and clinical implications. Periodontol 2000 2008;47:5166. 
Atatürk Üniv. Diş Hek. Fak. Derg.

J Dent Fac Atatürk Uni

Cilt:29, Sayı:1, Yıl: 2019, Sayfa, 80-88

12. Barewal RM, Oates TW, Meredith N, Cochran DL. Resonance frequency measurement of implant stability in vivoon implants with a sandblasted and acid-etched surface. Int J Oral Maxillofac Implants 2003:18:641-51.

13. Fischer K, Stenberg T, Hedin M, Sennerby L. Fiveyear results from a randomized, controlled trial on early and delayed loading of implants supporting full-arch prosthesis in the edentulous maxilla. Clin Oral Implants Res 2008;19:433-41.

14. Sjöström M, Lundgren S, Nilson H, Sennerby L. Monitoring of implant stability in grafted bone using resonance frequency analysis. A clinical study from implant placement to 6 months of loading. Int J Oral Maxillofac Surg 2005;34:45-51.

15. Huang HL, Chang YY, Lin DJ, Li YF, Chen KT, Hsu JT. Initial stability and bone strain evaluation of the immediately loaded dental implant: an in vitro model study. Clin Oral Implants Res 2011;22:6918.

16. Ohta K, Takechi M, Minami M, Shigeishi H, Hiraoka $M$, Nishimura $M$, Kamata $N$. Influence of factors related to implant stability detected by wireless resonance frequency analysis device. J Oral Rehabil 2010;37:131-7.

17. Degidi M, Daprile G, Piattelli A. Influence of underpreparation on primary stability of implants inserted in poor quality bone sites: an in vitro study. J Oral Maxillofac Surg 2015;73:1084-8.

18. Gehrke SA, Guirado JL, Bettach R, Fabbro MD, Martínez CP, Shibli JA. Evaluation of the insertion torque, implant stability quotient and drilled hole quality for different drill design: an in vitro investigation. Clin Oral Implants Res 2018;29:65662.

19. Gehrke P, Johannson D, Fischer C, Stawarczyk B, Beuer $F$. In vitro fatigue and fracture resistance of one- and two-piece CAD/CAM zirconia implant abutments. Int J Oral Maxillofac Implants 2015;30:546-54.

20. Lops D, Bressan E, Chiapasco M, Rossi A, Romeo E. Zirconia and titanium implant abutments for single-tooth implant prostheses after 5 years of function in posterior regions. Int J Oral Maxillofac Implants 2013;28:281-7.
BANKOĞLU GÜNGÖR, KARAKOCA NEMLİ, BAĞKUR, KOCACIKLI

21. Alqahtani F, Flinton R. Postfatigue fracture resistance of modified prefabricated zirconia implant abutments. J Prosthet Dent 2014;112:299305.

22. Guilherme NM, Chung KH, Flinn BD, Zheng C, Raigrodski AJ. Assessment of reliability of CADCAM tooth-colored implant custom abutments J Prosthet Dent 2016;116:206-13.

23. Kim JS, Raigrodski AJ, Flinn BD, Rubenstein JE, Chung $\mathrm{KH}$, Mancl LA. In vitroassessment of three types of zirconia implant abutments under static load. J Prosthet Dent 2013;109:255-63.

24. Stimmelmayr M, Edelhoff D, Güth JF, Erdelt K, Happe A, Beuer F. Wear at the titanium-titanium and the titanium-zirconia implant-abutment interface: a comparative in vitro study. Dent Mater 2012;28:1215-20.

25. Sugiura T, Yamamoto K, Kawakami M, Horita S, Murakami K, Kirita $T$. Influence of bone parameters on peri-implant bone strain distribution in the posterior mandible. Med Oral Patol Oral Cir Bucal 2015;20:e66-73.

26. Hansson S.The implant neck: smooth or provided with retention elements. A biomechanical approach.Clin Oral Implants Res 1999;10:394-405.

27. Roberts WE. Bone tissue interface. J Dent Educ 1988;52:804-9.

28. Frost HM. A 2003 update of bone physiology and Wolff's Law for clinicians. Angle Orthod 2004;74:315.

29. Cassetta M, Ricci L, Iezzi G, Dell'Aquila D, Piattelli A, Perrotti V. Resonance frequency analysis of implants inserted with a simultaneous grafting procedure: a 5-year follow-up study in man. Int J Periodontics Restorative Dent 2012;32:581-9.

30. Pieri F, Aldini NN, Fini M, Marchetti C, Corinaldesi G. Preliminary 2-year report on treatment outcomes for 6-mm-long implants in posterior atrophic mandibles. Int J Prosthodont 2012;25:279-89.

31. Ho DS, Yeung SC, Zee KY, Curtis B, Hell P, Tumuluri V. Clinical and radiographic evaluation of NobelActive (TM) dental implants. Clin Oral Implants Res 2013;24:297-304. 
Atatürk Üniv. Diş Hek. Fak. Derg.

J Dent Fac Atatürk Uni

Cilt:29, Sayı:1, Yıl: 2019, Sayfa, 80-88

32. Ostman PO, Hellman M, Sennerby L. Immediate occlusal loading of implants in the partially edentate mandible: a prospective 1-year radiographic and 4-year clinical study. Int J Oral Maxillofac Implants 2008;23:315-22.

33. Zhang Y, Sailer I, Lawn BR. Fatigue of dental ceramics. J Dent 2013;41:1135-47.

34. Korioth TW, Waldron TW, Versluis A, Schulte JK. Forces and moments generated at the dental incisors during forceful biting in humans. J Biomech 1997;30:631-3.

35. Rosentritt M, Hagemann A, Hahnel S, Behr M, Preis $V$. In vitro performance of zirconia and titanium implant/abutment systems for anterior application. J Dent 2014;42:1019-26.

36. Özdemir $H$, Bayındır $F$. İmplant stabilitesinin değerlendirilmesi: "rezonans frekans analizi". Atatürk Üniv Diş Fak Derg 2012;Suppl 5;98-104.

37. Tözüm TF, Turkyilmaz I, Bal BT. Initial stability of two dental implant systems: influence of buccolingual width and probe orientation on resonance frequency measurements. Clin Implant Dent Relat Res 2010;12:194-201.

38. Karl M, Irastorza-Landa A. Does implant design affect primary stability in extraction sites? Quintessence Int 2017;48:219-24.

39. Huang HL, Chang YY, Lin DJ, Li YF, Chen KT, Hsu JT. Initial stability and bone strain evaluation of the immediately loaded dental implant: an in vitro model study. Clin Oral Impl Res 2011; 22:691-8.

40. Ohta K, Takechi M, Minami M, Shigeishi H, Hiraoka $M$, Nishimura $M$, Kamata $N$. Influence of factors related to implant stability detected by wireless resonance frequency analysis device. J Oral Rehabil 2010;37:131-7.

41. Kheur MG, Sandhu R, Kheur S, Le B, Lakha T. Reliability of resonance frequency analysis as an Indicator of Implant micromotion: an in vitro study. Implant Dent 2016;25:783-8.

42. Falisi G, Severino M, Rastelli C, Bernardi S, Caruso S, Galli M, Lamazza L, Di Paolo C. The effects of surgical preparation techniques and implant macro-geometry on primary stability: An in vitro study. Med Oral Patol Oral Cir Bucal 2017;22:e2016.

43. Maeda $Y$, Satoh T, Sogo M. In vitro differences of
BANKOĞLU GÜNGÖR, KARAKOCA NEMLİ, BAĞKUR, KOCACIKLI

stress concentrations for internal and external hex implant-abutment connections: a short communication. J Oral Rehabil 2006;33:75-8.

44. Leutert CR, Stawarczyk B, Truninger TC, Hämmerle $\mathrm{CH}$, Sailer I. Bending moments and types of failure of zirconia and titanium abutments with internal implant-abutment connections: a laboratory study. Int J Oral Maxillofac Implants 2012;27:505-12.

45. Chun HJ, Yeo IS, Lee JH, Kim SK, Heo SJ, Koak JY, Han JS, Lee SJ. Fracture strength study of internally connected zirconia abutments reinforced with titanium inserts. Int J Oral Maxillofac Implants 2015;30:346-50.

46. Nakamura K, Kanno T, Milleding P, Ortengren U. Zirconia as a dental implant abutment material: a systematic review. Int J Prosthodont 2010;23:299309.

47. Sailer I, Zembic A, Jung RE, Siegenthaler D, Holderegger C, Hämmerle $\mathrm{CH}$. Randomized controlled clinical trial of customized zirconia and titanium implant abutments for canine and posterior single-tooth implant reconstructions: preliminary results at 1 year of function. Clin Oral Implants Res 2009;20:219-25.

48. Gehrke P, Alius J, Fischer C, Erdelt KJ, Beuer F. Retentive strength of two-piece CAD/CAM zirconia implant abutments. Clin Implant Dent Relat Res 2014;16:920-5.

49. Truninger TC, Stawarczyk B, Leutert CR, Sailer TR, Hämmerle $\mathrm{CH}$, Sailer I. Bending moments of zirconia and titanium abutments with internal and external implant-abutment connections after aging and chewing simulation. Clin Oral Implants Res 2012;23:12-8.

\author{
Yazışma Adresi \\ Merve Bankoğlu Güngör \\ Gazi Üniversitesi, Diş Hekimliği Fakültesi, \\ Protetik Diş Tedavisi Anabilim Dalı \\ Emek 8.cad Ankara \\ Tel: 03122034177 \\ e-mail: mervebankoglu@yahoo.com
}

